\title{
NOVAS FORMAS ECONÔMICAS: UM RELATO DAS TERRAS ALTAS DA PAPUA-NOVA GUINÉ*
}

Marilyn Strathern

Tanto os que se julgam exemplos do novo como os que se julgam exemplos do velho podem ser agentes radicais de mudança, pelo próprio fato de perseguirem essa distinção. Se existe aqui um tipo de congruência ou interdependência de esforços, isso talvez se deva ao que Otávio Velho descreveu como fait accompli da globalização. Desta, o autor coloca uma imagem concreta diante de nossos ol hos: para o antropólogo, a experiência seria análoga à visão de povos do mundo inteiro virando pentecostais (Velho 1996:101). A batalha entre Deus e o Diabo que o neopentecostalismo prega é um dualismo para desfazer outros dualismos. De resto, embora tenha sido um pastor de Hagen tido como luterano quem me abordou em 1995 com uma mensagem que desejava transmitir à Inglaterra, também ecoa em Hagen o comentário de Velho (1996:116) sobre o pentecostalismo se espalhando no Brasil por todo o campo religioso. As reuniões públicas da bem estabelecida I greja Luterana, assim como da Igreja Católica Romana, agora podem parecer com aquelas da muito mais recente Assembléia de Deus ${ }^{1}$, com sua promessa de carisma e fraternidade e seu trabalho em nome das semel hanças. Como disse o pastor, agora a Papua-N ova Guiné é um dos países mais cristãos do mundo, e eu devia voltar para a Inglaterra onde ele sabia que havia poucos crentes e levar o povo de volta a Deus.

Daquela perspectiva, este é um relato do passado. Não entrei na “nova fraternidade" dos anos 90. Pelo contrário, este é um relato de 1965: de como 1995 se parece da perspectiva de descrições que eram válidas então. Certamente, a Hagen de 1995 lembra a Hagen de trinta anos atrás, na medida em que as pessoas falavam da divergência do velho e do novo em suas vidas. Isso não é novo, mas agora parece uma divisão para desfazer outras divisões. É contra um tipo de batalha geracional que as pessoas proclamam a nova ordem. Para um euro-americano, o que pareceria o rastro de desenvolvimentos familiares, um novo tipo de indivíduo, de 
um lado, e maiores oportunidades de consumo, de outro, exige, contudo, alguma explicação do ponto de vista de 1965. Proponho que investiguemos a evolução de algumas relações em particular. Este artigo considera o indivíduo como um produto emergente do Estado, e o consumo como implicando um florescimento de certas relações de parentesco. Os três horizontes de tempo que se seguem refletem as circunstâncias do trabaIho de campo².

\section{Três horizontes}

Há trinta anos, em Hagen, em meados da década de 60, os processos de pacificação que haviam sido interrompidos pela Segunda Guerra M undial tinham tido efeito por toda a região das terras altas da Papua-Nova Guiné: sem guerra, as pessoas tranqüilamente absorvidas na vida cristã, embora fossem poucos os santuários, os consel hos governamentais locais acabavam de se estabelecer, e o café era introduzido como um produto para o mercado. Todos previam o fim do sistema moka - troca cerimonial entre grupos clânicos - e o avanço do comércio. De fato, alguns antropólogos argumentaram que o estilo de "liderança" do big man era adaptado à atividade empresarial. Os homens queriam lojas de comércio, e o governo deveria providenciar estradas. "Estradas" eram uma metáfora para o que as pessoas viam como um divisor dos costumes; o passado e o futuro eram ambos o presente, e se podia ser tanto uma pessoa do passado quanto do futuro3, seguir os costumes dos antepassados ou seguir os costumes do comércio.

N esse ínterim, na área setentrional de $\mathrm{M}$ elpa, em Hagen, os clãs acumulavam capital a partir do enorme afluxo de conchas preciosas que teve lugar com a abertura das terras altas pouco antes da Segunda Guerra. Os australianos tinham necessidade de mercadorias; em um dado momento, os habitantes das terras altas estavam extraindo cauri e outras pequenas conchas de uma reduzida fonte estrangeira a um montante aproximado de meio milhão por mês (Hughes 1978:315). Essas conchas configuravam o preço da noiva e outros pagamentos ligados ao ciclo de vida; sobretudo, estimulavam as trocas competitivas entre grupos clânicos fundadas, nos anos 60 , sobre o então retrocedente horizonte de guerra; o pagamento de homicídios era a racionalização subjacente das maciças dádivas moka.

A batata-doce cultivada era dividida entre os porcos e as pessoas, e, na troca, os porcos seguiam as conchas. Aos ol hos dos homens, tais tran- 
sações eclipsavam a atividade produtiva em que estavam envolvidos tanto eles próprios como as mulheres. Esse divórcio entre transação e produção seria um estímulo para a minha ênfase bem posterior na divisão relativa ao gênero entre as relações de mesmo sexo e as relações de sexo oposto. A transação dominava, primariamente, o ponto de vista dos homens em suas relações com outros homens, o que levava a uma atividade coletiva baseada nos clãs de um modo que não era verdadeiro nas relações de mesmo sexo entre as mulheres. As relações de sexo oposto, concernentes aos vínculos entre homens e mulheres e que sempre tinham um tom pessoal para eles e elas, exprimiam-se em termos de conjugalidade ou de parentesco. O que era verdadeiro no plano interpessoal, também o era na relação da pessoa consigo mesma: as pessoas podiam, por assim dizer, ajustar seus vários componentes - aspectos do corpo, comportamento - a um estado de mesmo sexo, ao passo que sua máscara de membros de clãs agnáticos paternos, ao mesmo tempo nutridos e protegidos por parentes maternos, fornecia, no mesmo golpe, um padrão de relação com o sexo oposto.

As relações de sexo oposto eram o foco dos interesses das mulheres, mais do que dos homens. Para os últimos, a questão era garantir uma base doméstica a partir da qual pudessem agir no mundo, ao passo que as mulheres exigiam dos homens o reconhecimento de seu trabalho. A divisão do trabal ho na horticultura — os homens abrindo as roças e as mulheres plantando e colhendo - era o idioma em cujos termos essa relação se apresentava como reciprocidade (desigual). As mulheres usavam tal vantagem como podiam, insistindo em suas reivindicações personalistas de outras maneiras; assim, o sangue derramado em uma briga levaria a reivindicações de compensação, geral mente satisfeitas quando o marido pagava aos seus parentes masculinos. Estruturalmente, as mulheres situavam-se "entre" grupos de homens - suas múltiplas lealdades manifestando uma multiplicidade constitucional das mentes. Por outro lado, os homens eram supostos vencerem suas emoções e orientações conflitantes muito mais facilmente, e exibirem a "mente una" que era a base para o sucesso das ações.

Dez anos depois, em meados da década de 70, o novo Estado emergente da Papua-N ova Guiné se defrontava, desde o seu nascimento, com um problema que ninguém havia previsto: o que se chamou "guerra tribal" nas terras altas. As razões eram muitas. Incluíam fronteiras el eitorais ampliadas, que tinham desestabilizado vel has alianças, e os altos preços do café, que tinham desviado as ambições dos homens dos estabelecimentos comerciais para o transporte de carga e passageiros, com o 
prejuízo de mortes nas estradas. Trabalhadores de fora de Hagen forneciam mão-de-obra para as vastas plantações de café e chá em processo de transferência da propriedade dos estrangeiros para a população local, e surgiam problemas quando imigrantes se envolviam em disputas (as pessoas de Hagen desprezavam o trabal ho assalariado - podiam lucrar mais com seu próprio café e a horticultura de mercado). Além do mais, o sistema judiciário introduzido mostrou-se inadequado para lidar com as dimensões políticas do homicídio, e as pessoas passaram a fazer justiça com suas próprias mãos. Os pagamentos por homicídio assumiram um novo caráter, com grandes somas sendo exigidas em dinheiro, e sendo pagas diretamente ao clã ou tribo da vítima pelo clã ou tribo do assassino. Alguns pagamentos podiam se transformar em troca moka - que certamente não tinha desaparecido como previsto - , mas, ao contrário desta, o esforço para a obtenção do valor desses pagamentos era semelhante ao envolvido na compra de um veículo: por mais que a moeda circulasse, ela não retornava às mãos dos doadores através de contradons 4 . Enquanto isso, as conchas estavam desaparecendo totalmente da região, desvalorizadas em face do dinheiro.

Se, com a chegada dos australianos, o afluxo de conchas teve um efeito democratizante, como argumentou Andrew Strathern, produzindo big men que tentaram em vão manter seu monopólio fazendo com que as conchas passassem por suas mãos, esse efeito incidia, contudo, especificamente sobre as relações entre os homens. A horticultura de mercado gerou um segundo efeito democratizante, e neste as mulheres também estavam envolvidas. Visto que o dinheiro entrava tanto em "pequenas" como em "grandes" quantidades, as mulheres não se importavam em ficar com as pequenas enquanto os homens controlavam as maiores. Conseqüentemente, as mulheres não apenas entraram em cena com seus próprios recursos (ainda que diminutos), mas também apareceram como sustentáculos visíveis dos homens de seu grupo, quando estes vinham pedir mais dinheiro. As mulheres possuíam dinheiro de uma maneira que nunca tinham possuído conchas. Ao mesmo tempo, era também possível aos homens negar a contribuição das mulheres para suas atividades; o porco, que tinha sido o símbolo por excelência do esforço conjugal, podia, se necessário, ser comprado.

N essa época (década de 70), eu estava escrevendo sobre a retórica do consumo (Strathern 1981). M anifesto, sobretudo, no desejo explícito das mul heres de criar porcos para comer, o consumo parecera-me fazer parte do ciclo de produção e consumo relativo às relações de sexos opostos personalistas, centradas na conjugalidade e no parentesco. Estas esta- 
vam tão isoladas quanto eclipsadas pela esfera da transação. Assim, quando primeiro escrevi sobre produção e transação, a produção subsumia o consumo. Mas agora estou focalizando o contraste retórico feito pelos homens entre produção e transação, de um lado, e consumo, de outro. J untas, produção e transação permitiram definir a nova esfera do empreendimento comercial (em pidgin, bisnis). No que se refere ao lucrativo café, por exemplo, tanto os homens quanto as mulheres eram produtores de dinheiro. Ideal mente, as al tas quantias de dinheiro dos homens eram destinadas a aquisições ou transações coletivas prestigiosas, a mais negócios ou "dinheiro-moka". Independentemente de o dinheiro se destinar a algo que, de acordo com a analogia da troca, poderia reverter para eles, ou não, a própria atividade de reunir o dinheiro envolvia um certo número de transações paralelas. Os homens contavam também com suas bases domésticas, exigindo as "pequenas" quantias das mulheres para suplementar suas transações. No entanto, as mulheres eram mais suscetíveis a gastar seu dinheiro com as crianças, com comida quando esta era escassa, com roupas, sabonete (mulheres gastando com sabonete e fazendo-se atraentes sendo uma fonte real de suspeitas), querosene, taxas escolares, e assim por diante. Esse "consumo" podia ser retoricamente construído como gasto pessoal, e era tido pelos homens como tipicamente feminino. Em contrapartida, as mulheres queixavam-se do consumo dos homens - devido à cerveja e à sua grande capacidade para desperdiçar altas somas de kinas (dólares) em atividades inúteis - , o qual contrastava com sua poupança virtuosa de toea (centavos) obtidos com dificuldade.

Enquanto isso, a terra estava sendo desviada da horticultura para o cultivo do café. Havia uma espécie de espírito pioneiro em relação ao “negócio" no novo Estado independente. Alguns M elpa setentrionais retornaram para se estabelecer na terra que já tinham ocupado ao longo das margens do rio Wahgi na região central de M elpa; o controle da malária, introduzido quando as terras altas foram abertas, e a drenagem do pântano Wahgi (para as plantações) tinham tornado o local habitável novamente. Se, por volta de meados da década de 70, o número de retornados tinha crescido substancialmente, em meados dos anos 90 esse novo assentamento estava no limite de sua capacidade populacional. $\mathrm{O}$ efeito da drenagem fora tornar cultiváveis vários terrenos ricos em turfa, que eram considerados extremamente férteis. Disseram-me que nesse tipo de terreno, em contraste com os estreitos solos montanhosos de M elpa setentrional, havia uma redução do intervalo entre o plantio e a col heita que, em alguns casos, era de cerca de um terço. A popularidade dessa área 
era ainda mais acentuada devido à sua proximidade da cidade de $\mathrm{Mt}$. Hagen ${ }^{5}$. Este era, basicamente, um lugar para fazer compras - ternos e jaquetas, fogões a querosene, calculadoras e gravadores, suplementos alimentares para engordar, material cristão em pidgin e inglês, refeições rápidas e passagens aéreas. Era também um lugar para vendas. M uito além das couves e batatas introduzidas na década de 50, o mercado ostentava produtos frescos, como brócolis, ervilha e berinjela. As mulheres almejavam o crescimento das transações, a fim de aproveitar os intermediários que levavam a produção de avião para M oresby6.

Em 1995, observei uma parcela de terra sendo cultivada. Sharleen trabalhava em uma lanchonete na cidade e sua intenção era tornar-se a única fornecedora de batatas do local. Ela contratou mão-de-obra nãoHagen (imigrantes desempregados que viviam na cidade) para o pesado trabalho de cavar e revolver o solo, trazendo mulheres da terra de seu marido para ajudar no plantio. Todos estavam satisfeitos em vê-la chegar, e fizeram disso um acontecimento. Antes que o plantio começasse, ela jogou fertilizantes químicos no solo negro de turfa. Sharleen tinha herdado a terra dos pais de sua mãe; esta vivia em M oresby, e só esporadicamente havia cultivado ali. O que não era usual: filhas geralmente reivindicavam a terra de seu pai, mas não a transmitiam; aqui, na ausência da filha, a filha da filha estava usando sua terra natal.

Outras irmãs/filhas tinham obtido não apenas os direitos de usufruto, mas de residência permanente ou semipermanente no novo assentamento ${ }^{7}$, dizendo, invariavelmente, que a terra era boa e que o dinheiro vinha fácil. Não era possível determinar em que medida essa concentração era um fenômeno difundido, mas certamente ela era acentuada nessa área. Reuniam-se ao assentamento não apenas as filhas, mas seus maridos e outros parentes que podiam reivindicar um vínculo através das mulheres. E não apenas aqueles provenientes de Hagen - havia uma apreciável população não-Hagen, do indonésio solitário, passando por todo um grupo das terras altas meridionais, até homens da província Enga casados com esposas Hagen ou aposentados do serviço público na cidade. Os residentes consideravam-se o grupo de maior crescimento na região.

Quatro pontos para concluir esta narrativa. Primeiro, as pessoas estavam se recuperando de uma série de mortes pelas quais vários clãs, com diferentes graus de responsabilidade, estavam pagando em porcos (valendo de 500 a 800 kinas, e o mais alto chegando a mil kinas) e dinheiro (podia-se exigir por um homicídio de 20 mil a 30 mil kinas). As pessoas estavam fartas de brigar e pagar; em lugar disso, reuniram-se em 
cultos carismáticos e irmandades (algumas congregações eram ramificações da igreja pentecostal), incentivadas pela proibição de bebida na província, o que facilitava o cumprimento da promessa de não beber, e pelo temor de que o céu e a terra acabassem no final do milênio. Segundo, o mercado era onipresente: não existia evento público que não atraísse filas de vendedores espalhando suas sacolas de náilon (sacos velhos de farinha de trigo) nas quais colocavam não só os refrescantes cana-de-açúcar e pepino, mas comida pronta, milho torrado, pãezinhos e bolinhos, batata-doce. As mulheres ganhavam razoáveis quantias com isso; um homem que chegasse tarde em casa podia comprar um lanche no caso de não haver comida, e os homens solteiros podiam alimentar-se de uma maneira que nunca tinha sido possível. Terceiro, a pressão sobre a terra em torno do assentamento era intensa. A parentemente, as áreas de forragem para os porcos estavam reduzindo mês a mês, e estes, em vez de ficarem perambulando durante o dia e fuçando todo tipo de comida, tinham de ficar presos. Isso exigia um trabalho muito intenso, pois era preciso removê-los de acordo com o sol, e as cordas constantemente se rompiam quando eles tentavam se libertar. Finalmente, os corpos das mulheres haviam mudado. Elas não estão se abaixando menos nas roças, creio, e continuam a carregar fardos, mas muitas não carregam mais bolsas sobre a nuca, o que dava um aspecto arqueado à sua postura, nem viram os pés e as pernas para dentro da maneira contida que costumavam fazer. Ao contrário, as mulheres andam com as cabeças descobertas e os braços balançando, e as adolescentes sentam-se de qualquer modo. As bolsas que hoje carregam são geralmente vívidas e decorativas; uma das primeiras visões que o turista tem no aeroporto de Hagen são as fileiras de bolsas coloridas à venda sobre a cerca. Para aqueles em busca de signos do relaxamento das mulheres, tal ênfase na decoração pode parecer tão irritante quanto o sabonete. Ao mesmo tempo, as bolsas tornaram-se um signo onipresente da tradição local, seja ela de "Hagen", das "terras

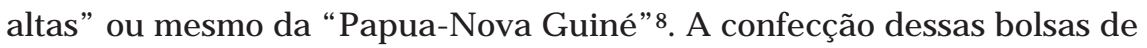
mulher, mas também das versões para homens, e dos chapéus a elas associados, talvez seja o único trabalho exclusivamente feminino que eu vi. A maioria das pessoas também está mais gorda.

Talvez isso soe familiar, uma história contada inúmeras vezes. Qual é seu interesse? 


\section{Pessoas divididas}

A discussão começa com uma observação que também é familiar: o dinheiro é divisível, multifuncional e uma medida de valor, bem como um meio de troca. A contece, porém, que esta é uma observação nova e, pelo menos para a pessoa que a faz, não familiar. N ão estou me referindo a notas para uma conferência sobre M alinowski ou Firth, mas àquilo que disse o irmão da mãe de Sharleen, Manga, no decorrer de várias conversas sobre mudança social.

No passado, observou Manga, as pessoas tinham conchas de cauri ou de madrepérola e não hesitavam: se um homem chegasse e solicitasse uma concha de madrepérola esta era dada a ele; ou, em caso de divórcio, tratando-se de uma devolução do preço da noiva, conchas e porcos eram reunidos e entregues a ele. $N$ ão havia nenhum outro uso para essas coisas 9 . Cada item era um todo. Era tanto uma coisa única como tinha uma única finalidade - ninguém pensava na possibilidade de reter parte de uma concha. Mas dinheiro é diferente. Há muitas coisas para se fazer com o dinheiro. Pode-se pensar em comprar comida, ou uma passagem de ônibus, ou em contribuir para um pagamento de reparação. Quando se trata de dar dinheiro a alguém, deseja-se ficar com uma parte. "Ele pediu 20 kinas, eu darei 10 kinas porque tenho outro uso para as outras 10 kinas". Do mesmo modo, o dinheiro pode ser dividido em pequenas quantias. Um homem tem 100 kinas, mas aí uma parte vai para isso, outra para aquilo, e a soma total já não existe mais. Idéias demais, disse $\mathrm{M}$ anga, acompanham seu uso. A utilidade do dinheiro encoraja as pessoas a se agarrarem às suas migalhas. $E$ se o dinheiro pode ser gasto em numerosas coisas, então numerosas coisas também têm um preço. Um homem olha para uma casuarina seca e pensa: “Oh, posso vendê-la para alguém que não tenha lenha". Um homem com uma roça abandonada olha para o mato crescendo e pensa que alguém pode querê-lo como palha. No passado, simplesmente pegávamos o capim - agora temos de comprar.

Idéias demais acompanham o seu uso: o dinheiro divide a mente. A noção de uma mente dividida é familiar aos habitantes de Hagen. Uma pessoa tem pensamentos conflitantes, e a ação consiste em convertê-los em um único que emerge como motivação. De fato, foi nesse contexto que argumentei alhures (1988:282) que a pessoa emerge como um agente individual: através da singularidade da ação. Da mesma maneira, um clã aparece como um indivíduo col etivo (Foster 1995a:10-11 diz esta frase a propósito dos Tanga da Nova Irlanda) quando está engajado em um 
empreendimento, quando age como uma unidade. É o ato que (através de sua temporalidade) individua 10 .

Ora, M anga estava floreando um pouco as coisas. No passado, o clã somente agia como uma unidade individual, reunindo-se como "um", através da supressão de sua constituição heterogênea (ver Hirsch 1995: 199)11. Qualquer dádiva de porcos ou conchas constituía uma contribuição, obtida com dificuldade, de pessoas que invariavelmente tinham outros usos para eles. M as M anga estava usando a singular demonstração da completude da concha e do porco para dizer algo acerca do dinheiro: dessa perspectiva, este não tinha um efeito individuante; o dinheiro estava sempre sujeito a alternativas. Assim, ao dar apenas uma parte, não se estava convertendo intenções conflitantes em um ato único, mas, ao contrário, estimulando as divisões da mente. Esta observação sobre a mente dividida fora induzida por uma reflexão sobre as pessoas divididas. Eu comentara que as pessoas pareciam estar disputando no tribunal o tempo todo, e M anga disse que tudo isso se resumia a dinheiro. Uma mulher espera de seu marido dinheiro, ele disse, e o marido espera de sua mulher tanto provisões, hoje chamadas "serviços" (savis), como auxílio nos empreendimentos, ou "reparação" (kompensesen) por injúria.

Eu aceito a análise de $M$ anga no que diz respeito à questão da divisão ou multiplicidade, a idéia de que o dinheiro poderia ser um todo se não fosse dividido ou fragmentado, de que está ligado a divisões dentro das pessoas - suas múltiplas orientações - e entre as pessoas - as expectativas das partes quanto a uma relação. A maneira pela qual o povo de Hagen formula muitas de suas reflexões a respeito da mudança apresenta um aspecto igualmente dualista. As pessoas também são apresentadas como tendo suas mentes divididas entre seguir velhas e novas estradas ${ }^{12}$.

Às vezes os antropólogos sociais abordaram a questão da mudança dividindo a cultura e a sociedade em pedaços, como se elas também pudessem ser um todo caso não fossem fragmentadas. Ter-se-ia uma sociedade inteira se ela não fosse dividida! N aturalmente, culturas e sociedades nem são completamente inteiras nem completamente divididas. A ssim como as pessoas. Isso é sabido por qualquer um que tenha vivido ou procriado em um sistema de metades exogâmicas, já que a divisão social mais significativa está inscrita na decoração de seus próprios corpos $^{13}$. Mas a compulsão euro-americana para pensar a sociedade como um todo implica identificar os conflitos "no interior", como no caso da identificação de uma tensão entre o novo e o velho. Com maior ou menor ironia, pedaços da cultura/sociedade serão analisados como tradicionais, 
e outros como modernos, contemporâneos, pós-coloniais, globais, ou o que quer que seja. Haverá ironia, pois os antropólogos sabem que a tradição só sobrevive se for reinventada, e sabem que uma tradição valorizada e explícita não é o mesmo que uma tradição não manifesta, implícita, visível apenas para o observador, porque, para seu portador, ela não é tradição, mas vida. A pessoa que, deliberadamente ou por apatia, segue os vel hos costumes, vive em um mundo que resiste à possibilidade dessa escolha. Em todo caso, sabe-se que a história é contínua.

Mas em Hagen as pessoas habitualmente acionam o que Gellner (1964) ${ }^{14}$ chamaria de uma concepção episódica e não evolucionista da história. Não se trata de "mudança" no sentido de desenvolvimento progressivo, mas do deslocamento de um tipo de socialidade para outro. A concepção vigora em diferentes planos.

Primeiro, o velho mundo já foi eclipsado pelo novo e as pessoas estão vivendo em um "novo tempo"; o novo está agora separado do velho em virtude do próprio fato de que contém tanto o velho quanto o novo. Segundo, esses tempos podem coexistir, como Hirsch descreveu para os Fuyuge. Eu entenderia a ênfase do povo de Hagen na oposição entre o vel ho e o novo como uma versão das socialidades alternadas que, na década de 60, eram subjacentes ao movimento entre os tempos ordinário e ritual, entre as orientações doméstica e política, entre as esferas da produção e da transação. Cada tempo ou tipo de engajamento social pode ser visto (ou antecipado, como observa Hirsch) a partir da perspectiva do outro. A mudança de perspectiva no decorrer desses momentos da vida social pode assumir a forma da reciprocidade, das relações doador/donatário, na medida em que, nestas, um, futuramente, se tornará o outro; ou, então, pode implicar um eclipse de identidades, como no movimento de transformação da produção doméstica em transação cerimonial. Terceiro, como as pessoas também adotam perspectivas umas sobre as outras, ocupando assim posições alternadas, é óbvio que cada pessoa traz em si mesma a capacidade de atuar, seguindo o vel ho ou o novo. Manga, alfabetizado em pidgin, animador de vários empreendimentos bisnis, com ambições na futura exploração comercial da terra em torno do assentamento, também se coloca como um tradicionalista, conservador dos velhos valores e guardião dos costumes. Por sua vez, seu filho Rupert, com educação superior e emprego permanente em M oresby, teria dito que também seguia o kastom ("costume") de Hagen por levar presentes para a mãe e a irmã, assim como para seu pai, quando ia para lá de férias. 


\section{Dois tipos de homens}

O trabalho era um tema da conversa local, estimulada pela atividade de transformação das antigas terras destinadas aos porcos em terrenos cultiváveis. Contaram-me que nos velhos tempos era possível conseguir pessoas para ajudar no trabalho com a promessa de ajuda recíproca. M as hoje em dia ninguém está disposto a trabalhar se não for remunerado. $\mathrm{O}$ que era especialmente verdadeiro quanto à geração mais jovem, para a qual, é claro, isso era um meio para a sua independência precisamente pela razão que os homens mais velhos vinham a explicitar: no passado, os jovens trabal havam porque mais tarde dependiam de ajuda, especialmente para o preço da noiva. Tanto os jovens quanto os vel hos reconheciam o contraste entre as gerações e entre a dependência e a independência das pessoas.

De fato, a ladainha da auto-estima brotava por toda parte. Os homens de meia-idade espantavam-se com a capacidade de os jovens ignorarem as exigências da reciprocidade. $O$ filho de $M$ anga, Rupert, parecia particularmente impermeável aos seus parentes. Sua mãe precisava de uma nova casa, e Rapa, um irmão que vivia no mesmo assentamento, construiu uma para ela, esperando que Rupert, ao retornar de M oresby, reconhecesse seu gesto. Rapa ficou tomado de surpresa ao descobrir que o jovem simplesmente não o levara em consideração15. O pai, sem entender por que o filho não se importava em investir nas relações para o dia de amanhã, pagou, ele próprio, pela casa, para que Rapa não ficasse sentido com Rupert. Ao retornar, Rupert ignorou completamente o trabalho agrícola que estava em andamento, e, além de não colaborar, não pagou ao pai e aos irmãos pelo trabalho que fizeram por ele. As pessoas que gastavam consigo mesmas ou que só trabal havam para ganhar dinheiro podiam ser acusadas de subtrair recursos do fluxo de reciprocidade. Via de regra, a reciprocidade engendra uma troca de perspectivas - cada pessoa vê a si mesma a partir do ponto de vista do outro. A dependência pode, assim, possuir uma conotação positiva quando envolve a mobilização das relações, e as pessoas ganham importância em função das relações nas quais se apóiam. Então, por que as queixas de M anga não conseguiram afetar Rupert, não tiveram a força que um dia podem ter tido?

No passado, a pessoa que negasse publicamente a importância das relações se colocava em um beco sem saída. $N$ ão ter relações era ser a escória, destino dos homens sem esposas, das mulheres sem parentes, ou dos homens que se afastavam da vida coletiva. Ser a escória significava não ter nada para colocar sobre a pele - a riqueza que engrandece uma 
pessoa -, motivo pelo qual as mulheres eram, como categoria, a escória. A pessoa desprovida de relações nem podia corresponder à retórica coletiva através da qual os big men, tentando levar os membros do seu clã a esquecer seus próprios assuntos e participar de um evento de grupo, amplificavam a unidade do clã, nem corresponder às retóricas múltiplas acionadas quando as pessoas estavam negociando seus interesses ou ampliando as riquezas do clã com recursos externos. Hoje, quando qualquer um pode perambular com roupas que denotam dinheiro, será que esses fins podem ser atingidos solitariamente? De um lado, o mercado consumidor permite a inflação da auto-estima; de outro, as pessoas podem multiplicar-se a si próprias através da série de produtos disponíveis para o consumo. Nesse caso, estaríamos de fato em um mundo familiar, em que é o mercado que oferece, em troca, uma perspectiva ao consumidor.

Trata-se aqui de mais do que um sentimento novo sobre objetivos individuais e independência pessoal. Lembremos a perda da unicidade observada por M anga na atualidade ${ }^{16}$. Esta era o eu individualizado visto da perspectiva externa do outro. A troca de dádivas poderia objetivar essa possibilidade ao separar o doador e o donatário; a troca mobilizava as relações coletivas; também mobilizava um amplo espectro de relações externas ao grupo, levando as pessoas para diferentes direções. Em tudo isso a troca de dádivas aparecia como um multiplicador de relações, o sustentáculo mesmo da reciprocidade. Contudo, são precisamente os desenvolvimentos nas práticas de troca ao longo dos últimos trinta anos ou mais que prefiguraram a auto-estima do consumidor.

\section{Dois tipos de relações}

Em um artigo clássico sobre Hanuabada, um assentamento M otu na saída de Port M oresby, na década de 70, Gregory (1980) distinguiu dois tipos de dádivas: para os homens e para Deus. O primeiro tipo reinsere as dádivas em um ciclo de trocas que mantém os bens em circulação (investimento nas relações), enquanto o segundo os retira de circulação. Gregory está se referindo às doações maciças dos clãs cristãos para as igrejas naquele período, doações feitas com grande publicidade e que preservavam a hierarquia dos clãs, a qual é a das dádivas motu, mas sem retorno para os doadores. Pode-se considerar al guns dos pagamentos reparatórios por homicídio como uma das "dádivas para Deus" em Hagen, hoje (década de 90). Do ponto de vista dos doadores, a riqueza sai de circulação. 
Enquanto no passado recente esses pagamentos eram freqüentemente 0 ponto de partida de relações de reciprocidade entre grupos, que mantinham a continuidade do fluxo, existe agora uma segunda alternativa que toma a forma de pagamentos não retribuíveis. Estes evocam uma reciprocidade de tipo específico, na medida em que são destinados a pacificar os donatários em troca da vida tirada e a abrandar sentimentos violentos de modo a evitar a vingança. Economicamente, contudo, funcionam, para os donatários, como capital que eles estão livres para investir em outras relações, e, para os doadores, ou como sacrifício17 ou como dádivas alienáveis em uma economia de mercado. Assim, em Hagen, as dádivas arquetípicas para os homens (reparação por homicídio) atualmente podem bem funcionar, para os doadores, como dádivas para Deus.

O contraste entre as transações que mantêm as riquezas em circulação e aquelas que retiram as riquezas de circulação corresponde a uma prática indígena pós-colonial: a divisão dos pagamentos reparatórios em "restituição" - a reparação pela vítima - e em uma quantia extra ("aperto de mãos") - para apaziguar os sentimentos (Strathern 1972:2526). Às vezes, esse extra era chamado baiim lo ("comprando/pagando a lei"), embora a expressão, como a própria kompensesen ("reparação")18, também pudesse ser aplicada ao pagamento como um todo. Nos anos 90, um equivalente do pagamento pela violação da lei era, dizia-se, o dinheiro deixado nas cortes locais para os juízes, de modo a compensá-los por seu transtorno. Embora possa haver uma diferença entre pagar para fazer uma pessoa sentir-se bem e pagar a um juiz, o fato de que, além da restauração da equivalência (restituição), uma quantia extra fosse paga, parece ser um fator significativo ${ }^{19}$. No mesmo sentido, a retirada de circulação da enorme riqueza necessária para a reparação por homicídio cria, para os doadores, uma relação específica para com o Estado. A reparação - restauração de uma equivalência - é apropriada como uma estratégia para evitar novos conflitos diruptivos ${ }^{20}$ : os governos nacional e provincial têm igualmente interesse em tais reparações. Sem o fim das retaliações, não podem garantir passagem livre para os compradores de café e para os veículos; não admitem, em algumas regiões, feridos de guerra nos hospitais. O Estado, podemos dizer, deseja encorajar um fluxo de sentimento voltado para ele próprio, de modo que as pessoas pensem na lei e na ordem e parem de se matar. Disso, já era talvez um prenúncio o sentimento público pelas vítimas de homicídio, no contexto de um fluxo de reparações em mão única.

Fluxos em mão dupla continuaram al hures. Ainda que possa parecer, nos anos 90, que a moka coletiva, no estilo de M elpa setentrional, 
não seja mais popular ou viável, falava-se de uma moka de outro tipo, no padrão da M elpa central, em que homens de clãs se reúnem em grupos para presentear seus respectivos parentes maternos. O fluxo de sentimentos entre parentes ligados por relações tão personalistas pode parecer a própria antítese dos sentimentos universalistas para com o Estadonação. Veremos que existem mais conexões do que se poderia supor.

\section{Fluxos de sentimento}

Se a reparação é para abrandar os sentimentos dos inimigos, fazêlos sentir-se calmos, tem-se seus idiomas como tomados de empréstimo dos sentimentos pessoais entre parentes ligados pelo casamento das mulheres. São essas as relações que implicam obrigações de parentesco, e prestações que acompanham os acontecimentos da vida, especialmente o preço da noiva e os pagamentos por morte. Nas décadas de 60 e 70 , aliados por casamento, que pagavam pela ajuda recebida nos conflitos, podiam invocar, como racionalização, a necessidade de manter boas relações com os parentes maternos.

Ora, na medida em que essas trocas coletivas entre grupos envolviam homens, podemos pensá-las como fundadas em relações de mesmo sexo, com toda a retórica da solidariedade fraterna que, para eles, esta forma de gênero continha. As mul heres, contudo, tinham um interesse especial nas trocas de seus maridos com seus parentes masculinos. Talvez isso não fosse surpreendente pois, em tais ocasiões, em lugar de estar dividida em função das demandas de homens diferentes - marido, irmão - a mulher achava-se, por assim dizer, reconciliada ("recomposta") pela conjugação dessas demandas nela própria. Portanto, dependendo da perspectiva adotada, tais trocas podem ser vistas como transações do mesmo sexo entre homens (p. ex., entre afins masculinos); ou então como mobilizando relações de sexo oposto (enfocando a mulher como elo de mediação). Quando a mulher era pensada como intermediária, as relações entre os homens também opunham um homem aos demais - as lealdades para com os seus agnatos e aquelas para com (digamos) os irmãos da esposa21. Em resumo, o desempenho das relações de sexo oposto entre homens (isto é, relações entre homens mediadas por uma mulher), que tinha um efeito de recomposição para a mulher, possibilitava, para um homem, tanto uma divisão de interesses quanto uma base de operações ampliada que ele "adicionava" às suas relações agnáticas. 
Essas duas posições de gênero se revelam principalmente nos pagamentos feitos aos parentes maternos. Como Wagner (1967) argumentou pela primeira vez em relação aos Daribi, uma das funções dos pagamentos aos parentes maternos em regimes patrilineares, como o de Hagen, é separar os agnatos de uma pessoa daqueles que tenham direitos sobre ela. Os parentes maternos que zelam pelo crescimento e desenvolvimento corporal dos filhos da irmã, e assim a eles se ligam corporalmente, são periodicamente compensados pelos parentes paternos por sua contribuição. Fazendo esses pagamentos, os agnatos definem a si mesmos (fazemse "um"). Conseqüentemente, os sentimentos de um homem se orientam para esses parentes cruzados nos próprios atos em que ele se destaca como distinto deles. Entre os Daribi, a criança é considerada como pertencendo realmente aos parentes maternos, a menos que os agnatos façam esse pagamento; em Hagen, trata-se muito mais de manter os sentimentos dos parentes maternos para com alguém fluindo de modo benevolente; assim eles continuarão a prestar favores e a fornecer alimentos22. Desse modo, os Hagen exploram as amplas possibilidades dessa relação: quando ami gáveis, os parentes maternos são uma fonte de apoio futuro. Em outras palavras, os homens Hagen enfatizam tanto a separação nas relações de mesmo sexo - grupos de homens fazendo reparações uns aos outros - quanto a vinculação nas relações de sexo oposto, o fluxo estimulado por um ato inicial de alimentação promovido por uma mulher. De fato, fiquei muito impressionada em 1995 com a constante ansiedade em assegurar que as pessoas se sentiam bem umas com as outras e consigo mesmas. Sem dúvida, isso era estimulado pela pregação pentecostal. Entretanto, quando pagamentos para os parentes maternos estavam em jogo, disseram-me que isto era essencialmente o kastom da PapuaNova Guiné. Mantive, portanto, o tempo presente.

A qui está Pamun, pai de várias crianças, atuante na associação de pais e mestres da escola local, invocando sua responsabilidade pessoal por encorajar famílias de outras províncias a se instalarem nas vizinhanças. Estávamos discutindo sobre as várias categorias de parentes beneficiados em uma festa (pati) dada por um homem idoso, para antecipar seu funeral e distribuir a herança em vida.

Quando alguém morre, disse Pamun (estou parafraseando), os parentes maternos próximos trarão um porco para que os enlutados comam, talvez também 100 kinas. $O$ dinheiro é para comprar comida durante 0 primeiro período de luto. Ao final deste (uma semana ou mais), os agnatos do morto retribuem aos parentes maternos, talvez 500 ou 800 kinas, muito mais que a quantia original. Kandere (do inglês "kindred", paren- 
tela, especificamente em referência a parentes por parte de mãe e irmãs) é uma coisa importante. Dizem: “Oh, o filho da nossa irmã morreu, e, se estivesse vivo, ele nos daria porcos e faria moka conosco, mas agora o homem morreu, e só ficaram os homens nascidos de outra mulher, e eles cuidarão dos seus próprios kandere". Assim, nós, os agnatos, pensamos nos sentimentos que os kandere desolados têm, e lhes damos presentes. Ou então os kandere acusam os agnatos por deixarem o homem morrer, e exigem reparação. (A questão dos maus sentimentos é que eles sempre têm efeitos futuros, de modo que os parentes maternos continuarão a ter um interesse nos parentes restantes, mesmo se o próprio filho da irmã é que tenha morrido. Se o pagamento (reparação) estimula sentimentos positivos, também pode servir para afastar sentimentos negativos, de modo que os agnatos serão deixados em paz.) Seja como for, ao longo de toda a sua vida, um homem deve fazer pagamentos para os parentes maternos. Eles reclamam caso uma pessoa não compre o corpo (baiim skin) desse modo. Essa é a velha lei. Na Papua-Nova Guiné, concluiu Pamun, kandere é uma coisa importante. Se não cuidarmos deles, eles não cuidarão de nós, e ficaremos doentes e morreremos.

Todavia, o tom normativo dessa afirmação é enganoso. Existe uma enorme margem de liberdade quanto a fazer ou não fazer tais pagamentos. De fato, existe uma segunda e crucial ordem de explicações, que Pamun também forneceu: presenteiam-se apenas aqueles parentes maternos com os quais são mantidas relações. Em outras palavras, se essas pessoas não visitam (e trazem presentes), nenhum presente é dado em troca. No caso do velho que estava celebrando a distribuição funerária de sua herança, seus próprios parentes maternos tinham desaparecido há muito tempo, e os presentes foram dados aos parentes maternos da geração seguinte. Dentre todos os parentes maternos que poderiam receber, são os que "trabalham" a relação que também "comerão" subseqüentemente ${ }^{23}$.

Como exortação, os Hagen podem apresentar o cuidado com os kandere como uma "tradição" (kastom) distintiva da Papua-Nova Guiné. Era como um autoproclamado tradicionalista que Manga estava planejando uma grande dádiva para os seus parentes maternos, articulada com aquela a ser feita por um de seus companheiros de subclã para os seus próprios parentes maternos que viviam alhures. A prestação conjunta constituiria um acontecimento. Ele explicou a lógica cultural: “essas pessoas nos alimentaram, nos deram o seio e, em troca, nós I hes damos porcos e dinheiro. Porque continuam a nos alimentar, e porque o fizeram quando éramos pequenos, compramos nossos corpos com pagamento". A final, um 
homem "gera" seu filho [mesmo termo para mulheres gerando filhos], e cuida dele em sua [do clã] terra, mas não é apenas o pai que está envolvido nisso; existe também a mãe! Ela também bore a criança $\mathrm{E}$ os parentes maternos vêem que os agnatos da criança estão felizes, mas se eles não pensarem na mãe, então, os pensamentos daqueles se tornarão um pouco raivosos (popokl). Da mesma maneira que a criança bebia no seio da mãe, eles (os kandere) também devem "comer". Ora, um parente materno de $M$ anga tinha obtido um primeiro pagamento com um presente de solicitação em porcos, e M anga já havia retribuído com um presente que incluía dois porcos cozidos e alguns vivos. Os porcos cozidos, comprados por 500-600 kinas cada, foram entregues com instruções especiais. Deveriam ser comidos especificamente pelos homens jovens de seu clã materno, que deveriam deixar as mandíbulas no cemitério; os espíritos do clã ol hariam então pelo filho de sua irmã (M anga). Os parentes maternos de $\mathrm{M}$ anga estão agora pressionando por uma prestação adicional. Ele encara o presente como estando na rubrica de moka (a reparação para os parentes maternos, culminando em moka). "Nós não damos mais moka da maneira como costumávamos fazer", ele acrescentou²4, e conjecturou que esta seria sua "última".

A ssim, M anga coloca as dádivas diretamente em uma órbita tradicional. Ele exprimiu nostalgia pelo desaparecimento da moka, e enfatizou o que os nativos da Papua-N ova Guiné pensam como kastom. Se ele o fez segundo uma escala inflacionada (ainda que pequena, como enfatizou para mim, em contraste com os tipos de pagamentos que se costumava fazer em M el pa central), isso se deve ao caráter inflacionário do valor atual das relações de sexo oposto em geral e das relações maternas em particular. Eu tomo esses dois focos de interesse como motores fundamentais da mudança econômica.

\section{Absorvendo o excesso}

A inflação em uma economia de mercado, baseada no consumo produtivo (ver Gregory 1982:31), implica reajustes segundo as proporções relativas de bens e dinheiro. O que seria a inflação em uma economia da dádiva, baseada na produção consumptiva? Presumivelmente, acarretaria mudanças nas taxas de reprodução das relações. A inflação em uma economia da dádiva poderia, assim, ser definida como um aumento na quantidade de coisas, bens ou dinheiro, em detrimento da capacidade que as relações têm de absorvê-las, ou seja, de se reproduzirem por meio delas. 
As relações expandem-se para acompanhar a crescente circulação das coisas. Podem se expandir mediante a intensificação das interações, reproduzidas, por assim dizer, a cada novo momento de objetivação ou atualização. O resultado não é, necessariamente, "mais relações"; pelo contrário, a premissa subjacente da reciprocidade ou das relações de obrigação pode simplesmente ser evocada com maior freqüência e segundo um nível mais elevado de demandas internas. Então, o que é passível de aumentar são as ocasiões em que as relações são ativadas. Como disse Manga, a presença do dinheiro introduziu muitas ocasiões novas para que maridos e esposas testassem a base de sua ajuda recíproca. A o contrário da divisão do trabal ho anual, o salário quinzenal ou a visita ao mercado criam expectativas de curto prazo. As expectativas de mutualidade são constantemente postas à prova.

M eu argumento será o de que, ao fornecerem um tipo de razão cultural para o consumo, as próprias relações que absorvem intensivamente os itens de consumo também permitem o desenvolvimento de consumidores com tendências individualistas de um tipo muito diferente. Quanto ao sentido que podemos atribuir ao novo individualismo, bem como ao novo consumismo, evoco em meu auxílio dois trabal hos recentes, o de Foster, sobre a formação da nação na M elanésia, e, mais rapidamente do que ele mereceria, o trabalho de Carrier sobre as teorias do consumo.

\section{0 indivíduo}

Foster (1995a; 1995b) desenvolve o paradigma dumondiano do (velho) indivíduo coletivo a fim de contrastá-lo com o (novo) indivíduo possessivo. Ele vincula este último à emergência do Estado-nação com sua série de qualidades abstratas e difusas às quais as pessoas aspiram, e que teoricamente podem ser possuídas por qualquer um. A propaganda contemporânea dirigida à classe média urbana da Papua-Nova Guiné encoraja as pessoas a pensarem em si mesmas a partir de suas práticas pessoais o que comem, o que ouvem no rádio, os quadrinhos que lêem -, que situam as pessoas em uma cultura nacional.

Existe uma ressonância entre o indivíduo coletivo de Foster e a identificação, feita pelos homens Hagen, de uma orientação individualizante com (e não contra) uma orientação coletiva: a capacidade de fazer-se ver, como por exemplo em uma transação, agindo com "uma mente" ou "um corpo". Quando, por outro lado, as pessoas da geração de M anga reclamam daquele que não pensou nos outros, evocam, ao contrário, o antigo 
indivíduo autônomo, sem relações, que seguia seu próprio caminho assumindo seu custo social. Eles só têm pena dessas pessoas. Hoje, alguns efetivamente se enquadram nessa categoria; em muitos outros casos, contudo, essa piedade é bem inútil. $E$ isso ocorre precisamente porque os novos indivíduos não são sem relações. Ao contrário, se olharmos de novo para o indivíduo possessivo descrito por Foster, fica claro que a orientação para si de tais pessoas encobre um conjunto muito real de relações. $O$ que o indivíduo possui é uma série de qualidades generalizáveis ("Eu sou como todas as pessoas que lêem jornal"; "a lei protegerá meu direito à liberdade") que constitui a base da relação que a pessoa mantém, enquanto indivíduo, com "o Estado", "a nação", "a sociedade" - cada uma dessas entidades abstratas apresentando um caráter ligei ramente distinto para os cidadãos, a população ou os membros. De acordo com essa visão, no indivíduo possessivo está incorporada assim uma capacidade relacional que atrai para ele ou ela, como argumenta Foster (1995b:165), os objetos a serem personalizados mediante seus atos de consumo. Isso é o análogo do relacionalismo melanésio, seu deslocamento e não sua antítese.

Existe uma estreita conexão na narrativa de Foster entre o indivíduo possessivo e o consumismo. Nos materiais que ele aborda (a representação dos habitantes da Papua-N ova Guiné na publicidade), as relações que se destacam são aquelas que dizem respeito ao mercado, e o mercado, ele argumenta, ao fornecer meios para imaginar a nação, também prepara as pessoas para as relações com o Estado. A população que lê jornais em $M$ oresby, respondendo a apelos diretos da cultura nacional e consumindo a idéia de um Estado nacional, percebe a si mesma como pertencendo a uma sociedade de cidadãos-consumidores similares ${ }^{25}$. Este é o seu mundo. Não é de surpreender que os homens mais vel hos em Hagen - assim como as mães e esposas -, em muitos casos, simplesmente, não cheguem a lugar algum com suas críticas àqueles que gastam seu dinheiro com o consumo de mercadorias disponíveis nacionalmente26.

Todavia, quando se trata de sustentar o kastom, na perspectiva de que diversas tradições locais (kastom) emergem como uma variação estilística no interior de um repertório cultural (kastom) (Foster 1992:284), jovens e velhos unem-se na valorização de certos tipos de ajuda recíproca. Os novos cidadãos apropriaram-se da idéia de solidariedade baseada na similaridade - como se buscassem seus wantok, aqueles com quem se compartilha uma linguagem, local de residência ou outra identidade de origem baseada na similaridade -, acompanhada de um al to valor à manutenção das relações com os kandere (parentes maternos) ${ }^{27}$. Ainda que possam ver estrangeiros operando um sistema wantok, encaram qual- 
quer coisa que tem a ver com os kandere como pertencendo essencialmente à Papua-Nova Guiné. De uma perspectiva Hagen, podemos dizer que os primeiros (wantoks) são assimilados a relações de mesmo sexo, e os segundos (kandere) a relações de sexo oposto. Nenhuma das pessoas mais velhas discordaria: essas relações de fato corporificam o kastom.

\section{Relações de sexo oposto}

Em sua análise do kastom como categoria cultural, Foster (1992) contrasta os Hagen e os Tanga da Nova Irlanda, indicando como, na década de 70, a moka Hagen incorporou as relações mercantis (bisnis) da mesma maneira como incorporou o dinheiro. Vimos que, nos anos 70, o bisnis e a moka se contrapunham ao consumo. Mas, se, então, os homens produziam para a troca e para as compras coletivas (a produção, incluindo-se aí o bisnis, destinava-se à "transação", ou seja, mais bisnis ou moka), nos anos 90 grande parte do trabalho de produção adapta-se explicitamente ao "consumo". Entre outras coisas, isso afeta a retórica de gênero. $O$ apelo dos homens para que outros homens (relações do mesmo sexo) investissem em transações costumava ser acompanhado da ênfase nos perigos do consumo como algo feminilizante e debilitante. Atualmente, o consumo (o gozo de bens de todos os tipos) parece possuir uma nova legitimidade.

Foster ressalta a pressão gerada pela "reprodução (social) ampliada" do tipo Hagen: o dinheiro permite que as pessoas ampliem sua participação na troca e engrandeçam o nome do doador. Retorno ao ponto da inflação inicial em conchas (décadas de 30 a 50) que provocou um florescimento das trocas cerimoniais, já que o acesso social a essas riquezas foi consideravelmente ampliado. Ao mesmo tempo, sobretudo durante a segunda onda inflacionária provocada pelo aumento do dinheiro em circulação nas décadas de 60 e 70, parecia que algumas pessoas se conduziam como se houvesse um "excesso" de dinheiro. Os big men diante dos homens comuns, e os homens como um todo perante as mulheres, mantinham a sua base de poder canalizando o dinheiro para empreendimentos coletivos, como a compra de carros. Isto, efetivamente, mandava o dinheiro para fora (para as mãos dos comerciantes de carros). As relações de troca de mesmo sexo entre os homens comportavam uma expansão desse tipo. Eles podiam levar a competição às últimas conseqüências, e isso não apenas acelerava a circulação como permitia que os homens, simultaneamente, juntassem o dinheiro, se livrassem dele e engrandecessem o nome do clã ao fazê-lo. 
Teria havido uma terceira onda de inflação? É isso que estamos verificando na década de 90 ? Uma inflação da capacidade de gastar com bens de consumo? Se for assim, outra série de relações instalou-se, por assim dizer, com um potencial de expansão que aumenta a capacidade de as pessoas absorverem bens de todos os tipos para todos os fins, não apenas os carros caros ou as reparações, que exigem grandes somas. E ainda que boa parte desse poder aquisitivo esteja fora da economia local (nas mãos de comerciantes estrangeiros), ela também garante um mercado local próspero, mantendo assim, plenamente, a circulação (mulheres vendendo pãezinhos). Essas são relações domésticas, mas relações domésticas de um tipo particular.

Carrier e seu colega Heyman ${ }^{28}$ criticaram recentemente a antropologia do consumo por não levar em conta as questões sociais, tomando como exemplo o mercado imobiliário norte-americano, cujos padrões de consumo não podem ser compreendidos sem que se entenda também os constrangimentos de status e classe, entre outros. Os autores situam corretamente o consumo nos quadros da reprodução social, em um contexto em que a unidade relevante é o grupo doméstico, embora sugiram que sua análise se aplica também a outros regimes de consumo. Seu modelo localiza o consumo nos esforços do grupo doméstico de situar a si mesmo em um mundo percebido como composto por grupos desiguais. O aburguesamento dos grupos domésticos na Revolução Industrial inglesa, com sua demanda por aparelhos de jantar, papel de parede e mobília para a sala, é bem conhecido. Esse grupo doméstico, como os indivíduos que o compunham, era tanto produtor quanto criador de práticas de consumo produtivo. Embora os bens do grupo doméstico e os itens associados ao que os euro-americanos consideram atividades domésticas sejam notáveis como bens de consumo na cidade de $\mathrm{Mt}$. Hagen, isso não implica em absoluto que o grupo doméstico seja a unidade social de consumo de tais bens. Isso não exclui os serviços locais que Carrier e Heyman mencionam, mas talvez Hagen esteja se tornando uma sociedade de consumo sem ter de desenvolver a casa toda equipada. $\mathrm{E}$ isso acontece porque aquilo que se oferece à expansão não faz parte das aspirações dos membros dos grupos domésticos. Quero destacar relações domésticas de outro tipo: relações de sexo oposto do ponto de vista de um homem e - embora eu não desenvolva muito esse tema - relações do mesmo sexo do ponto de vista de uma mulher.

O consumo de bens que se pode comprar foi confinado a um conjunto de relações cujo potencial de expansão é enorme. Essas relações domésticas personalistas são veículos muito apropriados para a progres- 
siva intensificação das interações. A escalada decorre não apenas da quantidade de bens de consumo disponíveis, mas da capacidade de essas relações crescerem e se expandirem em intensidade, variedade e atualização. Tal possibilidade, por sua vez, deriva do fato de tais relações dizerem respeito à continuidade dos bons sentimentos - mantendo um fluxo de sentimento entre parentes. A obrigação de cuidar dessas relações caracteriza os laços de sexo oposto H-W, F-D, B-Z, e em menor escala relações de mesmo sexo entre as mulheres, especialmente $M-D$, e também Z-Z. Um clã pode aumentar o número das ocasiões de troca cerimonial que organiza, mas só o fará em intervalos de meses ou anos; já as visitas entre consangüíneos e afins, com suas expectativas de hospitalidade, podem se tornar tão freqüentes quanto a ida à igreja na manhã de domingo ou ao futebol no domingo à tarde.

Isso pode ser relacionado com outros aspectos da vida social no novo assentamento. Tem havido um perceptível aumento no número de nãoagnatos que se estabelecem no território do clã, freqüentemente por intermédio de laços através das mulheres, estando os grupos locais inclinados a absorver as famílias que pretendem fazer um "contrato" (kontrak) com eles na expectativa de apoio financeiro e político. As crescentes exigências de auxílio recíproco entre maridos e esposas forneciam uma série de razões para o aumento da rotatividade dos cônjuges e do número de divórcios. $\mathrm{O}$ enfraquecimento das fronteiras territoriais (um grau mais elevado de disputas sobre os limites fundiários) e das regras de comensalidade (a reclusão menstrual não sendo mais praticada) exacerbou o sentimento de "aglomeração" de alguns retornados29. Em lugar do distanciamento, espaçamento e intervalos entre as relações que eram propiciados pelos padrões residenciais e por diversas regras de comportamento, talvez sejam necessárias novas reiterações das relações. O efeito é a intensificação das relações sob a forma das interações através das quais elas parecem se "reproduzir".

Por mais tradicionais que pudessem ser, os pagamentos de Manga aos seus parentes maternos também faziam parte dessa reconfiguração das relações de sexo oposto. $N$ ão quero dizer com isso que tenha havido um súbito afluxo de bens de consumo para a troca de dádivas, com a introdução da Pepsi e das roupas de esporte onde antes havia porcos e dinheiro. Em 1995, o preço da noiva, o preço do filho e outras dádivas mobilizavam os mesmos itens principais de vinte anos atrás. Os bens de consumo não eram de modo algum objetos de troca nesse sentido. Tudo o que as pessoas precisam é dinheiro (você não tem de negociar com itens de consumo se pode negociar com o meio que os adquire). Sob esse 
aspecto, a própria divisibilidade do dinheiro o torna "prático". M as por que se vincularia o dinheiro aos bens de consumo? O vínculo é pertinente no contexto dessas relações.

Especialmente em relação aos parentes maternos, mas também entre afins (futuros parentes maternos) e não-agnatos em geral, os laços construídos através das mulheres - tanto para os homens quanto para as mulheres - eram encarados, no passado, como potencialmente protetores/ameaçadores. Ainda que os homens sempre enfatizassem como seus filhos cresciam fortes na terra (agnática) de seu clã, esta era apenas uma parte da contribuição do clã agnático para a saúde e a vitalidade da pessoa em crescimento. Por outro lado, os kandere (parentes maternos) tinham um interesse particular no corpo da criança, pois era o corpo que eles "alimentavam", com leite materno, carne de porco e outros alimentos, e com dádivas; era o corpo que eles podiam ferir quando insatisfeitos com a maneira pela qual eram tratados; e era o corpo que os parentes paternos do morto pagavam para afastar a influência maligna. E é esse corpo, que era a manifestação material, a objetivação dessas relações substancializadoras, que serve igualmente como o novo corpo do consumidor.

Certa vez, Ru Kundil 30 exprimiu o contraste para mim. Eu estava falando sobre as vitaminas e remédios que servem para as diferentes funções corporais, e ele protestou contra a atenção que os europeus davam aos seus próprios corpos: “N ós [Hagen] não cuidamos deles", ele disse (estou parafraseando), "não dedicamos essa atenção aos nossos corpos". Ele propôs uma comparação com as roças:

“Os europeus plantam todos os diferentes tipos de comida, e assim terão sempre comidas diferentes [nas lojas]. M as nós [Hagen] não: não ambicionamos encher tudo com exemplares de todos os tipos, mas apenas com aquilo que queremos ou que está à mão. O importante é que distribuímos partes das roças para outras pessoas, dividimos a roça entre as pessoas [que tenham direito a ela]. É a isso que as pessoas aderem [como seu kastom]. Elas pensam em seus parentes maternos e afins e dividem a comida. A té nos velhos tempos de guerra, ele observou um tanto piedosamente, um grupo refugiado desconhecido podia chegar pedindo terra, e os anfitriões Ihes dariam roças e comida, e então posteriormente os imigrantes, gratos, retribuiriam aos anfitriões. Atualmente é que as pessoas não pensam assim, e os skulmen [os instruídos] guardam seu dinheiro no bolso e não o partilham. Fecham os ouvidos até mesmo aos pedidos daqueles que partilham de seu sangue, os irmãos de sua mãe". 
$\mathrm{N}$ a visão de Ru, se as relações estão em ordem, o corpo florescerá como seu signo. Você não cuida (como fazem os europeus) das partes do corpo, mas das condições para a boa saúde pessoal, as quais repousam nas relações que te sustentam. Uma pessoa deve ter um bom background (bekgraun), isto é, parentes. A diferença entre parentes paternos e maternos, desse ponto de vista, como Pamun também disse, é que os maternos têm de ser induzidos a fornecer alimentação/proteção. Ou seja, tais relações são um foco específico de reprodução. Você pode estar seguro que, crescendo na terra de seu pai, será alimentado por ela. M as você não pode ter certeza do interesse permanente dos parentes maternos, cujos favores só podem ser assegurados mediante um contato permanente e ativo. É por isso que essas relações têm um potencial de expansão, e é por isso que Manga se prejudicou pagando a Rapa, quando poderia, talvez, ter considerado a casa construída por ele como parte de sua obrigação enquanto residente não-agnato.

Há uma elevação geral da intensidade das relações através das mulheres, entre os homens e entre elas mesmas, diante da qual o reconhecimento público da importância dos parentes maternos atua como uma espécie de fundo cultural. Os parentes maternos importam-se com você se você se importar com eles, e em Hagen isso é visível no corpo, o que pode ter contribuído para a criação do corpo consumidor - cuja justificativa, no limite, não necessita de modo algum de relações entre as pessoas.

Em si mesmo e por si mesmo, o dinheiro não produz indivíduos possessivos, nem o que eu denominei de inflação da capacidade de absorver bens de consumo deriva simplesmente do valor evidente dos mesmos. As relações desenvolveram-se de certos modos específicos, e este artigo enfatizou um campo de relações de sexo oposto em expansão. Estas, ao mesmo tempo que criam um tipo de base para o surgimento de indivíduos possessivos e de cidadãos consumidores, também produzem um outro tipo de indivíduo.

Retornemos pela última vez à análise que Manga fez do dinheiro, seus comentários sobre o modo pelo qual o dinheiro se fixa. Um homem não pode se separar do dinheiro como se separava de uma concha (digamos) - e é esse processo de separação que faz dele um indivíduo, “um homem" doravante desligado das dívidas para com outros, encarnadas no bem valioso que é transmitido (cf. Gillison 1991; Weiner 1995). Podemos dizer que o dinheiro flui mais que as conchas (tudo tem seu preço), mas também que flui menos (as pessoas não podem dá-lo como um bem inteiro e agarram-se às suas migalhas). 
Como vimos, houve um tempo em que os pagamentos que os Hagen faziam aos parentes maternos desempenhavam a dupla função de isolar conjuntos de homens uns dos outros (homens que se dividiam mediante a reparação) e de manter um fluxo de sentimento entre parentes ligados através das mulheres, os quais podiam fornecer auxílio. $O$ primeiro era um exercício de separação - manifesta na concha que era dada inteira —, e o segundo era um exercício de manutenção da ligação - era preciso investir em tais relações a fim de concretizar seu potencial de crescimento futuro. O primeiro tinha um efeito individuante momentâneo, na definição discreta dos homens de ambos os lados; o segundo, um efeito agregador e diversificador, envolvendo as pessoas em suas transações compósitas. Mas, ao longo do tempo, o primeiro efeito individuante parece ter se tornado mais difícil de atingir em virtude do fato de que, nos anos 90, os indivíduos coletivos são menos, e não mais, evidentes; por toda parte vê-se indivíduos compósitos ${ }^{31}$. O florescimento de todos os tipos de relações de sexo oposto, para o qual os pagamentos de $\mathrm{M}$ anga aos seus parentes maternos contribuiu, criou diferentes pessoas sociais. Esses pagamentos de tipo moka para os parentes maternos passaram a se inserir em uma sociedade diferente.

Quem são, pois, essas pessoas? Como "um povo", elas realmente se tornaram um indivíduo compósito? Os retornados não se dividiram em unidades territoriais tão nítidas como outrora. Isto não quer dizer que os grupos não se reúnam em prol de objetivos comuns. Pelo contrário, um conglomerado de pessoas mantém-se unido por laços heterogêneos, de sexo oposto, assim como de mesmo sexo, Hagen e não-Hagen; a questão é que quaisquer pessoas que ali se incluam o farão a partir de uma relação específica e personalista que cultivaram. Para isso, precisam de dinheiro. Uma nova dignidade conferida à prosperidade (Velho 1996: 112)? Não é irrel evante que o mesmo tipo de indivíduo também esteja sendo produzido pelo atual entusiasmo para com o cristianismo de inspiração pentecostal: congregações de massas anônimas, nas quais cada membro aceita J esus individualmente em seu coração, unidas por meio de códigos pessoais, podem até ter o poder de livrar do Diabo os corpos das pessoas. Espantou-me a diversidade de algumas dessas reuniões, provenientes de numerosas tribos, províncias diversas, homens e mul heres, todas as idades. Nunca tinha visto algo assim antes. Cada pessoa com um diferente pecado, diz-se a elas, e cada uma buscando o mesmo deus da vida. 
Marilyn Strathern é William Wyse Professor of Social Anthropology na Universidade de Cambridge. É autora de Women in Between (1972), Kinship at the Core (1981), The Gender of the Gift (1988) e After Nature (1992). Seus trabal hos mais recentes são, como co-autora, Technologies of Procreation (1993) e, como editora, Shifting Contexts: Transformation in Anthropological Knowledge (1995).

\section{Notas}

* Minha enorme gratidão àqueles com quem fiquei por sete semanas em 1995, e todos os seus vizinhos. A visita foi possibilitada pelo N ational Research Institute, em Port M oresby; a British Academy deu-me uma bolsa de pesquisa. Keith Hart estimulou-me a apresentar uma versão preliminar deste artigo em um seminário em Cambridge. Sou grata a Eric Hirsch por seus comentários, e também a J ames Carrier, M ark M osko, Adam Reed e Dick Werbner.

1 Sob cuja égide o pentecostalismo inicialmente se expandiu. Ver Strathern (1993:169-174) para uma breve história desse período.

2 O trabalho de campo inicial, na atual província de Western Highlands, foi desenvolvido entre 1964 e 1965, na companhia de Andrew Strathern. Vivemos de modo intermitente na Papua-N ova Guiné durante a década seguinte, e minha última visita a Hagen ocorrera em 1976. A oportunidade para uma visita subseqüente mais longa só surgiu em 1995.

3 Glosando o título de McSwain (1977). Ver, também, Errington e Gewertz (1996).

4 Ao mesmo tempo, "na década de 70, a introdução do dinheiro na moka levou à recriação da troca", especialmente entre antigos aliados de guerra (Strathern 1993:213).

5 Declarada, em 1995, a “terceira cidade” da Papua-N ova Guiné.

6 M as o excesso de comida no mercado desencorajava algumas; havia sempre mais do que podia ser vendido, e freqüentemente não se obtinha mais que 10 ou 12 kinas. Há vinte anos, na época da colheita do café, um homem que viajasse tinha de levar apenas uma pequena sacola de café para vendê-lo ao longo do caminho; os homens do novo assentamento podem levar um cacho de bananas para o mercado de Hagen para conseguirem 10 ou 12 kinas. 
7 As casas eram construídas muito mais próximas do que ocorria anteriormente, dando a impressão de que estavam dispostas regularmente por uma vasta região; as pessoas denominavam esses agrupamentos, em pidgin, "villages" [aldeias].

8 Em seu estudo sobre a prisão de Bomana, em Port M oresby, Adam Reed (comunicação pessoal) descobriu que as mulheres presas começavam a trabalhar fazendo tais sacolas, aprendendo a fazê-las quando provinham de regiões onde essa tradição não existia.

9 Ponto de vista de um homem sobre a troca; os homens sempre tentavam estendê-lo aos porcos, e com isso se enredavam em disputas com as mulheres.

10 Da forma como defini esses termos, uma pessoa é uma relação, é andrógina e é o produto de ações. A pessoa aparece como um indivíduo em conseqüência de um processo de unificação (interna ou externa), e, assim, como sendo de um sexo ou do outro.

11 O ponto é, naturalmente, que no momento da transmissão a concha incorpora a "unidade" produzida nesse ato, isto é, a heterogeneidade é suprimida. A exposição de Weiner a respeito da singularidade da concha para os Foi contempla essa possibilidade. Aqui, permaneço fiel às minhas primeiras idéias a respeito da ligação e da separação, mas também aceito, para Hagen, a idéia de Weiner de que essas são metáforas não reconstruídas para "a projeção de uma forma assumida pelos atos completos de consumo produtivo na vida social Foi" (Weiner 1995:27).

12 Como no filme da BBC1, A Death to Pay For [Uma M orte a Ser Paga], de Charlie Nairn, transmitido em 11 de novembro de 1995. O jovem Nykint descreve como sua mente está dividida entre pensar no que pode roubar e pensar em ir à igreja. A divisão é representada como algo a respeito do qual ele, por assim dizer, não pode fazer nada, ainda que suas ações o levem para um caminho ou para o outro.

13 O que remete o antropólogo a uma antiga questão (cf. J osephides 1992): o papel desempenhado pelo observador externo na explicitação das práticas varia, evidentemente, em função do que já é explícito. Quando as divisões são apenas implícitas, o conflito, dissimulado pelas práticas sociais, pode ser desvelado. Quando a divisão e o conflito são explícitos, podemos buscar as conexões implícitas que uma tal divisão mantém. A primeira possibilidade é atraente para o senso comum dos euro-americanos que gostam de desvelar a "realidade" do conflito por baixo de uma límpida aparência de harmonia; a segunda produz os argumentos funcionalistas mais rígidos presentes, por exemplo, no trabalho de RadcliffeBrown sobre as relações jocosas e de evitação (ver Foster 1992:287 sobre a representação autoconsciente das práticas de troca no Pacífico).

${ }^{14}$ Citado no contexto da Papua-N ova Guiné por M cDowell (1985). 
15 Uma parenta visitara Rupert em M oresby e Rapa mandara uma mensagem por ela; a quantia enviada por Rupert, no entanto, foi irrisória. Um panorama, traçado a partir de M oresby na década de 70, é fornecido em Strathern (1975).

16 Ser um indivíduo, um agente resoluto com a mente una, em contraste com ser um compósito, pleno de desejos e relações heterogêneas, compreendia modalidades de existência alternativas. Se os euro-americanos habitualmente consideram a si mesmos como indivíduos em estado permanente de singularidade, talvez a ansiedade dos homens Hagen fosse serem mantidos em um estado permanente (não-reprodutivo) de heterogeneidade.

17 Ver Gregory (1980:630) sobre os Hanuabada, que disseram a ele que esses pagamentos eram "dádivas" (no sentido euro-americano de dádivas alienáveis) e que seria errado tirar proveito delas.

18 Uso a ortografia do jornal Wantok.

19 O "aperto de mãos" foi, assim, em certo sentido, o precursor dos pagamentos para o Estado.

20 Ver Strathern (1994:62) sobre o tratamento dos órgãos do Estado como um superclã.

21 Nenhuma contradição inevitável aqui: um homem pode expandir os recursos dos seus agnatos atraindo seus afins. Refiro-me aqui a uma divisão entre orientações sociais.

22 Receber alimentos é necessário, mas arriscado - esse não é um ato apenas benigno (Strathern 1988).

${ }^{23}$ Alguém que descobre que as pessoas que imaginava serem seus parentes maternos não possuíam laços de sangue com ele (mas de adoção, por exemplo), ainda assim continuará a enviar-Ihes presentes caso elas o tenham alimentado.

24 Os habitantes da região central de Melpa sempre organizaram a moka dessa maneira, com diversos membros de um subclã ou de um clã, combinando presentear seus respectivos parentes maternos em uma mesma ocasião.

25 “Grupos de status definidos em termos de padrões de consumo imaginados e idealizados" (Carrier e Heyman 1995:19).

${ }^{26}$ Quando Rupert retornou a M oresby estava todo equipado com "roupas de Hagen" (compradas em Mt. Hagen; ele havia chegado com "roupas de M oresby") - incluindo os presentes de três homens do seu grupo de idade casados ou prestes a se casar com algumas de suas irmãs. Manga manteve-se deliberadamente fora disso; esse era um problema da geração mais jovem. 
27 Um sentimento que, em tese e do ponto de vista dos grupos domésticos formados apenas pelo casal, sustentaria tanto regimes matri quanto patrilineares.

28 Sou grata a J ames Carrier pela permissão de citá-lo aqui. Ver, também, Carrier (1995).

29 E essa era uma razão para que muitos permanecessem na região setentrional de Melpa, a despeito da maior dificuldade em ganhar dinheiro.

30 Seu verdadeiro nome. A proveito a ocasião para agradecer pessoalmente a Ru por suas incontáveis gentilezas e por sua disposição em partilhar suas idéias. Uma autobiografia, originalmente escrita por Ru em pidgin e traduzida por Andrew Strathern, foi publicada pelo Institute of Papua N ew Guinea Studies em 1993. Os outros nomes desse relato são pseudônimos, e alguns detalhes pessoais foram disfarçados.

31 Dadas as minhas primeiras formulações, isso é um solecismo terminológico deliberado (uma congruência entre a pessoa compósita, singular mas dividida, e o indivíduo coletivo e indiviso).

\section{Referências bibliográficas}

CARRIER, J ames. 1995. Gifts and Commodities: Exchange and Western Capitalism since 1700. London: Routledge.

e HEYMAN, Josiah. 1995. Consumption and Political Economy. Universities of Durham \& Michigan. Mimeo.

ERRINGTON, Frederick e GEWERTZ, Deborah. 1996. “The Individuation of Tradition in a Papua New Guinean M odernity". American Anthropologist, 98:114-126.

FOSTER, Robert J . 1992. "Commodization and the Emergence of Kastam as a Cultural Category: A New Ireland Comparative Case". Oceania, 62:284-294. 1995a. Social Reproduction and History in Melanesia: Mortuary Ritual, Gift Exchange and Custom in the Tanga Islands. Cambridge: Cambridge University Press.

. 1995b. "Print Advertisements and Nation-Making in Metropolitan Papua New Guinea". In: R. J . Foster (ed.), Nation Making: Emergent Identities in Postcolonial Melanesia. Ann Arbor: University of Michigan Press. pp. 151-184.

GELLNER, Ernest. 1964. Thought and Change. Chicago: Chicago University Press.

GILLISON, Gillian. 1991. “The Flute $M$ yth and the Law of Equivalence: Origins of a Principle of Exchange". 
In: M. Godlier e M. Strathern (eds.), Big Men and Great Men: Personifications of Power in Melanesia. Cambridge: Cambridge University Press. pp. 174-196.

GREGORY, Christopher. 1980. “Gifts to Men and Gifts to God: Gift Exchange and Capital Accumulation in Contemporary Papua New Guinea". Man (n.s.), 15:626-652.

.1982. Gifts and Commodities. London: Academic Press.

HIRSCH, Eric. 1995. “Local Persons, Metropolitan Names: Contending Forms of Simultaneity among the Fuyuge, Papua New Guinea". In: R. J. Foster (ed.), Nation Making: Emergent I dentities in Postcolonial Melanesia. AnnA rbor: University of Michigan Press.

HUGHES, Ian. 1978. “Good Money and

Bad: Inflation and Devaluation in the Colonial Process". In: J . Specht e P. White (eds.), Trade and Exchange in Oceania and Australia. Mankind (número especial), Sydney. pp. 308-318.

J OSEPHIDES, Lisette. 1992. “Supressed and Overt Antagonism: A Study in Aspects of Power and Reciprocity among the Northern Melpa". Research in Melanesia (Occasional paper). Port M oresby: University of Papua New Guinea.

MCDOWELL, N ancy. 1985. "Past and Future: The Nature of Episodic Time in Bun". In: D. Gewertz e E. L. Schieffelin (eds.), H istory and Ethnohistory in Papua New Guinea. Oceania Monograph 28.

MCSWAIN, Romola. 1977. The Past and Future People: Tradition and Change on a New Guinea Island. M elbourne: Oxford University Press.

STRATHERN, Andrew. 1993. Voices of Conflict. Pittsburgh: University of Pittsburgh.
1994. “Crime and Compensation: Two Disputed Themes in Papua New Guinea's Recent History". Political and Legal Anthropology Review, 17:55-65.

STRATHERN, M. 1972. “Official and Unofficial Courts. Legal Assumptions and Expectations in a Highlands Community". New Guinea Research Bulletin, 47, Canberra.

. 1975. “No Money on our Skins. Hagen Migrants in Port M oresby". New Guinea Research Bulletin, 61, Canberra.

1981. "Self-interest and the Social Good: Some Implications of Hagen Gender Imagery". In: S. Ortner e H. Whitehead (eds.), Sexual M eanings. The Cultural Construction of Gender and Sexuality. Cambridge: Cambridge University Press. .1988. The Gender of the Gift. Problems with Women and Problems with Society in Melanesia. Berkeley/Los Angeles: University of California Press.

VELHO, Otávio. 1996. “Globalization: Object, Perspective, Horizon" . In: L. E. Soares (ed.), Cultural Pluralism, Identity, and Globalization. Rio de J aneiro: UNESCO/ISSC/EDUCAM . pp. 98-125.

WAGNER, Roy. 1967. The Curse of Souw. Chicago: Chicago University Press. WEINER, J ames. 1995. The Lost Drum: The Myth of Sexuality in Papua New Guinea and Beyond. Madison: University of Wisconsin Press. 


\section{Resumo}

Se a inflação em uma economia de mercado implica reajustes na proporção entre bens e dinheiro, a inflação em uma economia do dom deve implicar reajustes na proporção na qual são produzidas as relações. Este artigo trata das mudanças ocorridas nas terras altas da Nova Guiné, nos últimos trinta anos, e de como poder-se-ia interpretar o modo pelo qual certas relações estão se desenvolvendo. Estas relações são aquelas entre clãs, parentes e sexos. Ainda que o artigo abarque três horizontes temporais nesse período, ele é escrito deliberadamente da perspectiva de como o presente (a década de 90) apresenta-se a partir do passado (a década de 60).

\section{Abstract}

If inflation in a commodity economy implies a readjustment in the ratio of goods and money, then inflation in a gift economy must imply a readjustment in the rate by which relationships are produced. This article considers changes in the New Guinea Highlands over the last 30 years, and how one might interpret the manner in which certain relatioships are evolving. These are relations between clans, among kin and across the sexes. While the article considers three time horizonts over this period, it is deliberately written from the perspective of how the present (1990's) looks from the past (1960's). 